\title{
Stromal-epithelial lactate shuttle induced by tumor-derived interleukin-1 $\beta$ promotes cell proliferation in oral squamous cell carcinoma
}

\author{
JIE WU, YUN HONG, TONG WU, JUAN WANG, XIAOBING CHEN, ZHI WANG, BIN CHENG and JUAN XIA \\ Department of Oral Medicine, Guanghua School of Stomatology, Guangdong Provincial Key Laboratory of Stomatology, \\ Sun Yat-sen University, Guangzhou, Guangdong 510055, P.R. China
}

Received August 28, 2016; Accepted October 24, 2017

DOI: $10.3892 /$ ijmm.2017.3267

\begin{abstract}
Stromal-epithelial lactate shuttle is an essential process to support fast-growing tumor cells, however, the underlying mechanism remains ambiguous. Interleukin-1 $\beta$ (IL-1 $\beta$ ), which is a key node gene in both stromal and epithelial cells of oral squamous cell carcinoma (OSCC), may participate in this metabolic reprogramming. In the present study, anaerobic glycolysis of cancer-associated fibroblasts (CAFs) was evaluated and the role of IL-1 $\beta$ in regulating stromal-epithelial lactate shuttle was determined. A co-culture system of primary fibroblasts and OSCC cell lines (CAL27, UM1 or SCC25) was created to investigate the stromal-epithelial interaction. $\alpha$-smooth muscle actin ( $\alpha$-SMA) expression of fibroblasts, IL-1 $\beta$ expression and cell proliferation of OSCC cells, and a series of glycolytic genes were measured. Recombinant IL-1 $\beta$ treatment and IL-1 $\beta$ knockdown in UM1 cells were also used to evaluate the effect of IL-1 $\beta$. Expression of $\alpha$-SMA, glucose transporter 1, hexokinase 2, lactic dehydrogenase and mono-carboxylate transporter (MCT) 4 were significantly overexpressed in activated fibroblasts, while IL-1 $\beta$ and MCT1 were upregulated in OSCC cells, indicating enhanced glycolysis in cells of the tumor stroma and a lactate shuttle to the tumor cells. Furthermore, exogenous IL-1 $\beta$ induced
\end{abstract}

Correspondence to: Professor Bin Cheng or Professor Juan Xia, Department of Oral Medicine, Guanghua School of Stomatology, Sun Yat-sen University, 56 Lingyuan West Road, Guangzhou, Guangdong 510055, P.R. China

E-mail: chengbin@mail.sysu.edu.cn

E-mail: xiajuan@mail.sysu.edu.cn

Abbreviations: OSCC, oral squamous cell carcinoma; CAFs, cancer-associated fibroblasts; NFs, normal fibroblasts; IL-1 $\beta$, interleukin-1 $\beta ; \alpha$-SMA, $\alpha$-smooth muscle actin; GLUT1, glucose transporter 1; HK2, hexokinase 2; LDHA, lactic dehydrogenase; MCT1, mono-carboxylate transporter 1; MCT4, mono-carboxylate transporter 4; CFSE, carboxy-fluorescein succinimidyl ester

Key words: interleukin-1 $\beta$, cancer-associated fibroblasts, oral squamous cell carcinoma, glycolysis, lactate shuttle fibroblasts to present similar expression profiles as that in the co-culture system. Silencing of IL-1 $\beta$ significantly abrogated the regulatory effect of UM1 cells on stromal glycolysis. Additionally, carboxy-fluorescein succinimidyl ester cell tracing indicated that OSCC cell proliferation was accelerated during co-cultivation with fibroblasts. These results indicate that tumor-derived IL-1 $\beta$ enhanced stromal glycolysis and induced one-way lactate flow from the tumor mesenchyme to transformed epithelium, which promotes OSCC proliferation.

\section{Introduction}

Rapidly growing tumors have large energy demands, but the insufficient nascent vasculature fails to provide sufficient nutrition and metabolic substrates for malignant progression. Thus, cancer cells induce adjacent activated fibroblasts to increase lactate production via the glycolysis pathway. Subsequently, the cancer cells use metabolic intermediates release from fibroblasts to 'fuel' tumor growth $(1,2)$. This reciprocal metabolic reprogramming between cancer cells and the surrounding stroma has been widely recognized as a 'reverse Warburg effect' (3). As the most common metabolic intermediate of glycolysis, lactate is transported via unidirectional mono-carboxylate transporters (MCTs). This 'lactate shuttle' was first reported between astroglial cells and neurons through MCT1 and MCT2 transporters, respectively $(4,5)$. In the tumor microenvironment (TME), MCTs control the lactate exchange between glycolytic and oxidative cancer cells, and between stromal and epithelial cells (5). In the past decade, research has revealed a one-way flow of lactate shuttling from tumor mesenchyme to epithelium (6). This lactate fluxion has essential roles not in adjusting intracellular acid-base balance $(7,8)$, and also providing metabolic fuel for cancer cells.

Oral squamous cell carcinoma (OSCC) is the most common oral malignancy with poor 5-year survival rate (9). Components of the tumor stroma, particularly cancer-associated fibroblasts (CAFs), may be partially responsible for the unfavorable therapeutic results and poor prognosis of OSCC. This raises the questions, is the 'reverse Warburg effect' involved in OSCC progression? Does the stromal-epithelial lactate shuttle 'fuel' oral cancer growth? In our previous study, bioinformatics network construction identified interleukin-1 $\beta$ (IL-1 $\beta$ ) as 
one of the key node genes in the TME during oral carcinogenesis (10). Is this tumor derived-IL-1 $\beta$ a major contributing factor for the lactate flux to cancer cells?

In this study, it was aimed to investigate the function of cancer cell-derived IL-1 $\beta$ on reciprocal metabolic reprogramming between the epithelium and mesenchyme. Thus, a co-culture system was created using OSCC cells and separated fibroblasts from patients or healthy volunteers, and the results revealed that interactions between stromal and epithelial cells upregulated IL-1 $\beta$ expression in tumor cells, which enhanced glycolysis and lactate release in CAFs, which subsequently resulted in accelerated malignant cell proliferation.

\section{Materials and methods}

Cell lines. UM1, SCC25 and CAL27 human OSCC cell lines and normal oral keratinocyte (NOK) were used in this study. SCC25 and CAL27 were purchased from American Type Culture Collection (Manassas, VA, USA). OSCC cell line UM1 and NOK were provided by Professor J. Silvio Gutkind (University of California, San Diego, CA, USA). UM1, SCC25 and CAL27 were maintained in Dulbecco's modified Eagle's medium (DMEM; Gibco; Thermo Fisher Scientific, Inc., Waltham, MA, USA) containing 10\% fetal bovine serum (FBS; Gibco; Thermo Fisher Scientific, Inc.). NOK cells were maintained in Keratinocyte-SFM (Gibco; Thermo Fisher Scientific, Inc.). Cells were incubated at $37^{\circ} \mathrm{C}$ in $5 \% \mathrm{CO}_{2}$. This study was approved by the Ethical Review Committee of Guanghua School of Stomatology, Hospital of Stomatology, Institute of Stomatological Research, Sun Yat-sen University (Guangzhou, China; approval no. ERC-2012-15). All procedures performed in studies involving human participants were in accordance with the ethical standards of the institutional and/or national research committee and with the 1964 Helsinki declaration and its later amendments or comparable ethical standards. And all participants provided written informed consent to take part in the study.

Sample selection and primary cell culture. Fibroblasts separated from patients with OSCC, patients with oral leukoplakia and healthy volunteers, were termed CAFs $(\mathrm{n}=8)$, Dysplasia-fs $(n=8)$ and normal fibroblasts (NFs; $n=10)$, respectively. All samples were obtained from Department of Oral and Maxillofacial Surgery, Guanghua School of Stomatology, Sun Yat-sen University between February 2014 and September 2015. All patients provided written informed consent to participate in this study. Samples were cautiously washed with phosphate-buffered saline and then digested with $0.2 \%$ neutral protease Dispase II (Roche Diagnostics GmbH, Mannheim, Germany) overnight at $4^{\circ} \mathrm{C}$. The stromal layer was carefully split from the epithelial layer and shredded into tiny fragments. The fragments were digested with $0.25 \%$ trypsin-EDTA (Gibco; Thermo Fisher Scientific, Inc.) at $37^{\circ} \mathrm{C}$ for $1 \mathrm{~min}$. Following neutralization, centrifugation (at $120 \mathrm{x}$ g for $5 \mathrm{~min}$ ) and re-suspension at room temperature (RT), fragments were seeded into flasks and incubated in primary culture medium (DMEM containing penicillin, streptomycin and 20\% FBS) at $37^{\circ} \mathrm{C}$ for $\sim 14$ days. Subsequently, the fibroblasts were sub-cultured and purified according to the 'adherent time lag' between fibroblasts and epithelial cells. Fibroblasts between passage 4 and 10 (P4-P10) were used.
Co-culture system and fibroblasts activation. OSCC cells and fibroblasts were seeded onto the insert or the bottom well of co-culture Transwell inserts (Corning Incorporated, Corning, NY, USA), respectively, and independently cultured until the cells adhered. The co-culture durations are slightly different between the experiments, and the specific time has been noted in each figure. Once adhered, the insert was placed back into the well for co-culture.

Immunofluorescence (IF) staining. Cells were fixed with pre-cooled $100 \%$ methanol for $20 \mathrm{~min}$ at $-20^{\circ} \mathrm{C}$, following permeabilizing [using $0.1 \%$ Tween-20 and $1 \%$ bovine serum albumin (BSA; Beyotime Biotechnology, Shanghai, China)] for $10 \mathrm{~min}$ at RT and antigen blocking for $30 \mathrm{~min}$ ar RT, cells were successively incubated with mouse monoclonal anti- $\alpha$-smooth muscle actin ( $\alpha$-SMA; cat. no. ab7817; Abcam, Cambridge, MA, USA; diluted 1:200) at $4^{\circ} \mathrm{C}$ overnight, secondary antibody H\&L DyLight ${ }^{\circledR} 488$ (cat. no. ab96875; Abcam; diluted 1:200) at RT for $1 \mathrm{~h}$, and $100 \mathrm{ng} /$ ml DAPI (Sigma-Aldrich; Merck KGaA, Darmstadt, Germany) at RT for 5 min. Images were acquired with a confocal microscope (Carl Zeiss AG, Oberkochen, Germany).

Glucose uptake and lactate assays. The conditioned media (CM) was harvested and stored at $-80^{\circ} \mathrm{C}$. Glucose and lactate content were measured with a glucose assay kit (Applygen Technologies, Inc., Beijing, China) and lactate assay kit (Nanjing KeyGen Biotech, Co., Ltd., Nanjing, China), respectively, according to the manufacturers' protocols. Absorbance values of test groups were normalized against protein concentrations $(n=3)$.

IL-1 $\beta$ ELISA assay. CM from NOK and OSCC cell lines was harvested after $48 \mathrm{~h}$ incubation. IL-1 $\beta$ was measured with ELISA kit (cat. no. SEA563Hu; Cloud-Clone Corp., Katy, TX, USA) according to the manufacturer's protocol. The values were normalized to the cell count $(n=3)$.

Reverse transcription-quantitative polymerase chain reaction $(R T-q P C R)$. Total RNA was extracted using TRIzol reagent (Thermo Fisher Scientific, Inc.) and then reverse transcribed using qScript cDNA synthesis kit (Roche Diagnostics $\mathrm{GmbH}$ ). All of the primers were produced by Takara Biotechnology Co., Ltd. (Dalian, China; Table I). qPCR was performed using the the LightCycler ${ }^{\circledast} 480$ SYBR-Green I Master and the LightCycler ${ }^{\circledR} 480$ instrument (Roche Diagnostics GmbH). PCR was carried out at $95^{\circ} \mathrm{C}(10 \mathrm{~min})$ and 45 cycles at $95^{\circ} \mathrm{C}(10 \mathrm{sec})$, $65^{\circ} \mathrm{C}(15 \mathrm{sec})$ and $72^{\circ} \mathrm{C}(15 \mathrm{sec})$. Each step was performed according to the manufacturers' protocols. The amounts of target genes were normalized to GAPDH using $2^{-\Delta \Delta C q}$ calculations (11).

Western blotting. Cells were harvested and lysed in radioimmunoprecipitation assay buffer and measured with bicinchoninic acid protein assay kit (both from Sigma-Aldrich: Merck KGaA). Then samples $(30 \mathrm{mg} / \mathrm{lane})$ were separated by $10 \%$ SDS-PAGE and transferred to a polyvinylidene difluoride membrane. Following antigen blocking in 5\% nonfat milk for $1 \mathrm{~h}$ at RT, the membrane was incubated with primary antibodies overnight at $4^{\circ} \mathrm{C}$. The following primary antibodies were used: Rabbit monoclonal anti- $\alpha$-tubulin (cat. no. 2125; diluted 1:1,000), anti-GAPDH (cat. no. 2118; diluted 1:1,000), anti-hexokinase 2 (HK2) (cat. no. 2867; diluted 1:1,000), anti-lactate dehydrogenase (LDHA; cat. no. 3582; 
Table I. Primer nucleotide sequences.

\begin{tabular}{|c|c|c|}
\hline Gene & $\begin{array}{l}\text { Primer nucleotide } \\
\left.\text { sequences (5' to } 3^{\prime}\right)\end{array}$ & $\begin{array}{l}\text { Product } \\
\text { size (bp) }\end{array}$ \\
\hline GAPDH & $\begin{array}{l}\text { F: GCACCGTCAAGGCTGAGAAC } \\
\text { R: TGGTGAAGACGCCAGTGGA }\end{array}$ & 138 \\
\hline GLUT1 & $\begin{array}{l}\text { F: GCCTGAAGTCGCACAGTGAATAA } \\
\text { R: GCTCATTGGGCCCATACAAAG }\end{array}$ & 145 \\
\hline HK2 & $\begin{array}{l}\text { F: CTCAACCATGACCAAGTGCAGAA } \\
\text { R: CCTTGCGGAACCGCTTAGAG }\end{array}$ & 97 \\
\hline PFKM & $\begin{array}{l}\text { F: GCCAGTCTAATTGCCGTTCC } \\
\text { R: TACCAACTCGAACCACAGCC }\end{array}$ & 212 \\
\hline PKM2 & $\begin{array}{l}\text { F: CCACTTGCAATTATTTGAGGAA } \\
\text { R: GTGAGCAGACCTGCCAGACT }\end{array}$ & 148 \\
\hline LDHA & $\begin{array}{l}\text { F: ATCTTGACCTACGTGGCTTGGA } \\
\text { R: CCATACAGGCACACTGGAATCTC }\end{array}$ & 180 \\
\hline MCT1 & $\begin{array}{l}\text { F: TTATCCTGCCACACCAGCAG } \\
\text { R: TGCTGTCACACACAGACACA }\end{array}$ & 352 \\
\hline MCT4 & $\begin{array}{l}\text { F: ATTGGCCTGGTGCTGCTGATG } \\
\text { R: CGAGTCTGCAGGAGGCTTGTG }\end{array}$ & 243 \\
\hline IL-1 $\beta$ & $\begin{array}{l}\text { F: TCGCCAGTGAAATGATGGCTTA } \\
\text { R: GTCCATGGCCACAACAACTGA }\end{array}$ & 197 \\
\hline
\end{tabular}

GLUT1, glucose transporter 1; HK2, hexokinase 2; PFKM, phosphofructokinase, muscle; PKM2, pyruvate kinase M2; LDHA, lactate dehydrogenase; MCT, mono-carboxylate transporter; IL-1 $\beta$, interleukin-1 $\beta$; F, forward; $\mathrm{R}$, reverse.

diluted 1:1,000) and anti-IL-1 $\beta$ (cat. no. 12703; diluted 1:1,000) all from Cell Signaling Technology, Inc. (Danvers, MA, USA); mouse monoclonal anti-MCT1 (cat. no. sc-365501; diluted 1:200) and rabbit polyclonal anti-MCT4 (cat. no. sc-50329; diluted 1:400) from Santa Cruz Biotechnology, Inc. (Dallas, TX, USA); mouse monoclonal anti-glucose transporter 1 (GLUT1) (cat. no. 202921; diluted 1:250) from R\&D Systems, Inc. (Minneapolis, MN, USA). The membrane was then washed three times with TBS-Tween, and incubated with secondary antibodies goat anti-rabbit IgG (cat. no. 7074; diluted 1:2,000) or horse anti-mouse IgG (cat. no. 7076; diluted 1:2,000) both from Cell Signaling Technology, Inc. for $1 \mathrm{~h}$ at RT, according to the source of primary antibodies. The immune-reactive bands were visualized with an enhanced chemiluminescence system (EMD Millipore, Billerica, MA, USA). Band intensities were semi-quantitated using ImageJ software (National Institutes of Health).

Small interfering RNA (siRNA)-mediated downregulation of $I L-1 \beta$. IL-1 $\beta$ siRNA (si-IL-1 $\beta$ ) was designed by and purchased from Invitrogen (Thermo Fisher Scientific, Inc.). Cells were transfected with siRNA pool (including the following sequences: IL-1 $\beta$-siRNA 1 forward, 5'-GCUCGCCAGUGAA AUGAUGGCUUAU-3' and reverse, 5'-AUAAGCCAUCAUU UCACUGGCGAGC-3'; IL-1 $\beta$-siRNA2 forward, 5'-GGAUGA CUUGUUCUUUGAAGCUGAU-3' and reverse 5'-AUCAGC UUCAAAGAACAAGUCAUCC-3'; IL-1 $\beta$-siRNA3 forward, 5'-GGAUAUAACUGACUUCACCAUGCAA-3' and reverse 5'-UUGCAUGGUGAAGUCAGUUAUAUCC-3') or Stealth
$\mathrm{RNAi}^{\circledR}$ negative control (cat. no. 12935200) by Lipofectamine ${ }^{\circledR}$ RNAiMAX reagent (Invitrogen; Thermo Fisher Scientific, Inc.). UM1 cells $\left(1 \times 10^{6} / \mathrm{ml}\right)$ were cultured in 6 -well plates with DMEM containing $10 \%$ FBS for $24 \mathrm{~h}$ and maintained in a $37^{\circ} \mathrm{C}$ incubator under a humidified atmosphere containing $5 \% \mathrm{CO}_{2}$ (until the density of the transfected cells reached 30-80\%). The siRNA or negative control were transfected into the cells using Lipofectamine ${ }^{\circledR}$ RNAiMAX at $10 \mathrm{nM}$ according to the manufacturer's instructions. The transfection efficiency was confirmed by RT-qPCR and western blot analysis (data not shown).

Proliferation assay with carboxy-fluorescein succinimidyl ester (CFSE). On the basis that CFSE cell fluorescence progressively decreases as cells divide, UM1 cell proliferation was determined using CFSE. Cells were re-suspended in $1 \mu \mathrm{M}$ CellTrace $^{\mathrm{TM}}$ CFSE staining solution (Invitrogen; Thermo Fisher Scientific, Inc.), and incubated at $37^{\circ} \mathrm{C}$ for $20 \mathrm{~min}$, protected from light. Then 5 times the original staining volume of complete culture medium was added to the cells and the mixture as incubated at $37^{\circ} \mathrm{C}$ for a further $5 \mathrm{~min}$ to terminate the staining reaction. Following three washes with culture media, UM1 cells were co-cultured with fibroblasts for $72 \mathrm{~h}$ or cultured alone as the control. UM1 cells were detached from the plates and fixed with $4 \%$ paraformaldehyde at $24 \mathrm{~h}$ intervals at RT. Subsequently, the CFSE fluorescence was detected by flow cytometry (Beckman Coulter, Inc., Brea, CA, USA) with an excitation light of $488 \mathrm{~nm}$. Results were expressed as a proliferation index (mean level of cell divisions frequency), using ModFit V3.0 software (Verity Software House, Topsham, ME, USA).

Statistical analysis. Data are presented as the mean \pm standard deviation from at least three independent experiments. Statistical analysis of the data was performed by Student's t-test, one-way ANOVA using SPSS 17.0 software (SPSS, Inc., Chicago, IL, USA). P $<0.05$ (two-tailed) was considered to indicate a statistically significant difference.

\section{Results}

Glycolysis is increased in activated fibroblasts from patients with oral carcinogenesis. To investigate the biological characteristic of fibroblasts isolated from oral premalignant and malignant lesions, IF staining for $\alpha$-SMA was performed. A marked increase in $\alpha$-SMA expression was observed in Dysplasia-fs and CAFs, compared with negative/low expression in NFs (Fig. 1A). These results indicated that fibroblasts were activated during oral carcinogenesis. Additionally, glucose and lactate assay kits were used to measure the levels of fibroblasts glycolysis. Glucose utilization and lactate production were increased significantly in CAFs compared with NFs (Fig. 1B).

Enhanced stromal glycolysis is cancer cell-dependent. To evaluate the association between stromal glycolysis and oral cancer cells, NFs and UM1 cells were co-cultured using a Transwell insert for $48 \mathrm{~h}$, and then $\alpha$-SMA staining was performed on the fibroblasts. As shown in Fig. 2A, fibroblasts were activated following cultivation with oral cancer cells and $\alpha$-SMA expression of co-cultured fibroblasts was increased compared with fibroblasts without co-cultivation. 
A

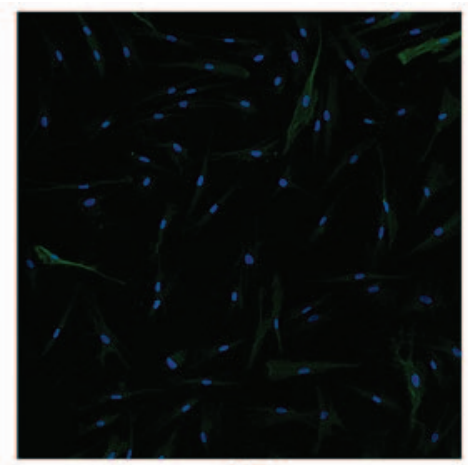

NFs

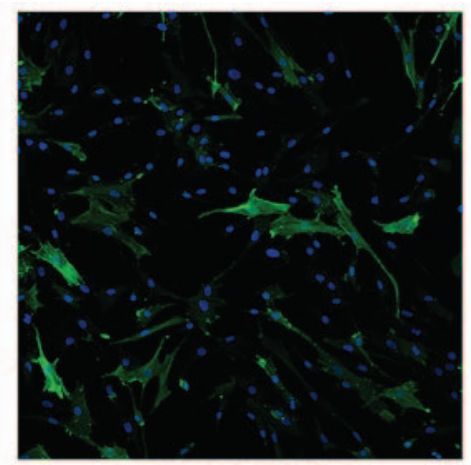

Dysplasia-fs

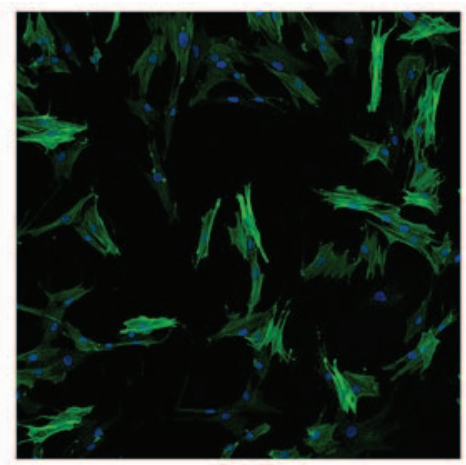

CAFs

B

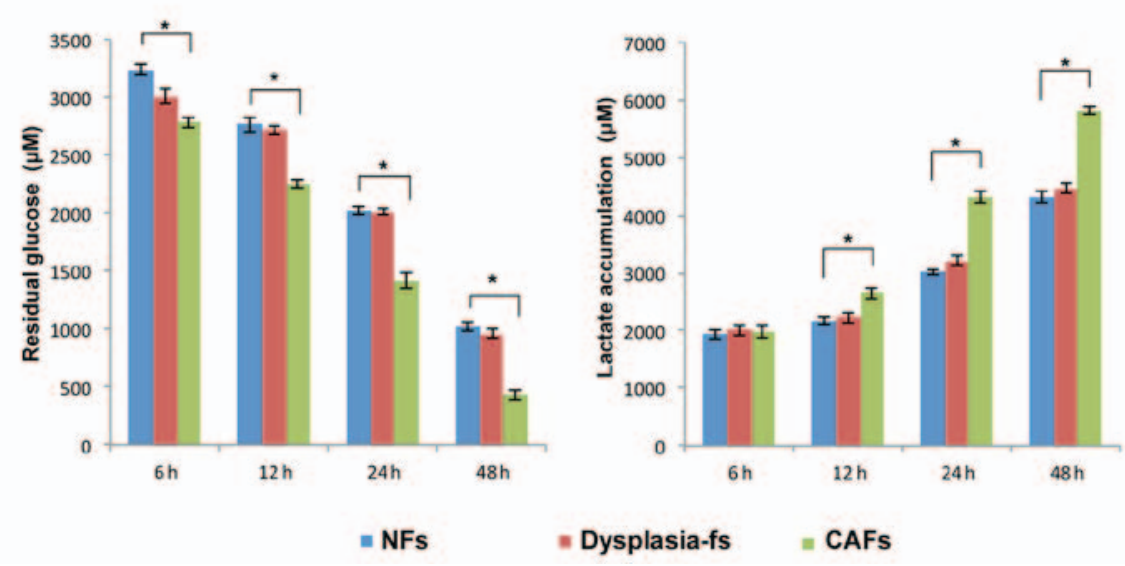

Figure 1. Glycolysis increases activation of fibroblasts in oral carcinogenesis. (A) Immunofluorescence staining of $\alpha$-smooth muscle actin (green) in NFs, Dysplasia-fs and CAFs from transforming oral tissues. Nuclei were counterstained with DAPI (blue). Magnification, x400. (B) Residual glucose (left) and lactate production (right) in conditioned media of fibroblasts. Supernatants were harvested at $6,12,24$ and $48 \mathrm{~h}$. The data are presented as the mean \pm standard deviation of triplicate experiments. ${ }^{*} \mathrm{P}<0.05$. NFs, normal fibroblasts; Dysplasia-fs, oral leukoplakia fibroblasts; CAFs, cancer-associated fibroblasts.

Activated fibroblasts were harvested after $48 \mathrm{~h}$ co-culture with CAL27, UM1 and SCC25 for subsequent analysis of glycolysis-associated gene expression. RT-qPCR and western blot results (Fig. 2B and C) showed that GLUT1, HK2, LDHA and MCT4 expression was increased in activated fibroblasts compared with fibroblasts cultured alone. Among these genes, GLUT1 was significantly upregulated with the highest fold change of mRNA level. Taken together, these data indicated that OSCC-activated fibroblasts displayed enhanced glycolysis, accompanied by an increase the expression of glycolysis associated genes. In our previous study, IL-1 $\beta$ was identified as a key node gene in OSCC progression, and elevated IL-1 $\beta$ expression was parallel with oral carcinogenesis (10). Thus, does IL-1 $\beta$ participate in stromal glycolysis induced by oral cancer cells?

$I L-1 \beta$ secretion from oral cancer cells is increased by activated fibroblasts. IL-1 $\beta$ mRNA expression was significantly increased in OSCC cell lines, compared with NOK cells (Fig. 3A). ELISA results demonstrated that UM1 and SCC25 cells secreted more IL- $1 \beta$ than NOK cells, and particularly that IL-1 $\beta$ secretion of UM1 was nearly twice that of NOK (Fig. 3B). However, CAL27 cells exhibited elevated IL-1 $\beta$ expression at the mRNA level only, with no significant alteration in IL-1 $\beta$ secretion detected by ELISA. Furthermore, when OSCC cells were co-cultured with fibroblasts (NFs), all the OSCC cell lines in our experiment expressed increasing IL-1 $\beta$ in a time-dependent manner, moreover, and UM1 cell was the most sensitive to the stimulation of fibroblasts (Fig. 4). Accordingly, the UM1 cell line was selected for subsequent IL-1 $\beta$ siRNA transfection experiments.

Enhanced stromal glycolysis in OSCC may be $I L-1 \beta$-dependent. To determine the effect of IL- $1 \beta$ on tumor metabolism, IL-1 $\beta$ antagonists (IL-1Ra) was used to neutralize secreted IL- $1 \beta$ in the supernatant, and IL- $1 \beta$ siRNA was used to knock down endogenous IL-1 $\beta$ in OSCC cells, whereas exogenous recombinant human IL-1 $\beta$ was used to promote IL-1 $\beta$-induced effects. OSCC cells and fibroblasts were treated with human recombination IL-1 $\beta(20 \mathrm{ng} / \mathrm{ml})$ alone or both IL-1 $\beta(20 \mathrm{ng} / \mathrm{ml})$ and IL-1Ra $(20 \mathrm{mg} / \mathrm{ml})$. CM were harvested at 6,12, 24 and $48 \mathrm{~h}$. No significant change in glucose consumption and lactate production was identified in OSCC cell lines following treatment. However, NFs and CAFs exhibited significantly increased glucose consumption after $24 \mathrm{~h}$ of IL-1 $\beta$ treatment, and lactate accumulation increased was after IL-1 $\beta$ treatment for $24 \mathrm{~h}$ in NFs and $48 \mathrm{~h}$ in CAFs. However, IL-1Ra significantly attenuated the IL-1 $\beta$-induced effects on glucose consumption and lactate production in fibroblasts (Fig. 5A). Fibroblasts were harvested after IL-1 $\beta$ treatment for $48 \mathrm{~h}$, and RT-qPCR assay was performed to investigate the expression of glycolysis-associated genes. As shown in Fig. 5B, GLUT1 and HK2 expression was significantly increased in the IL-1 $\beta$ treated group of NFs and CAFs. MCTs changed synergistically, with decreased expression of 
A

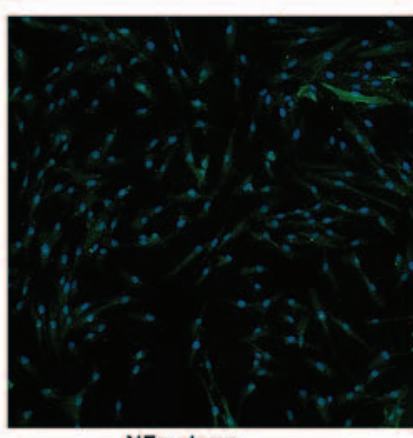

NFs alone

B

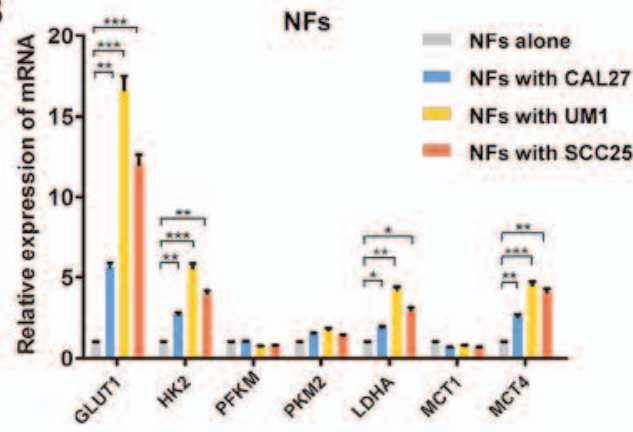

C

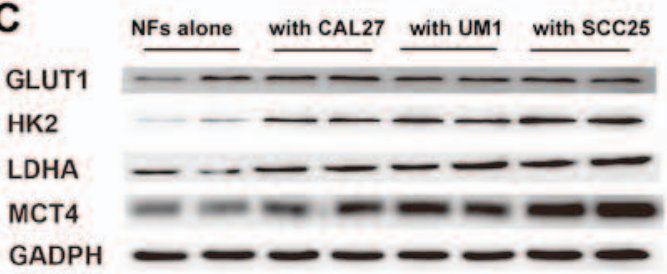

GLUT1

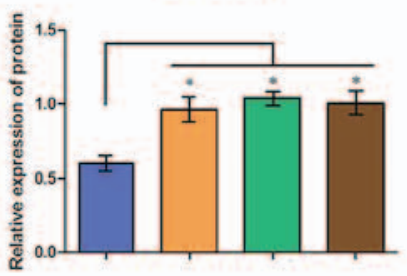

LDHA

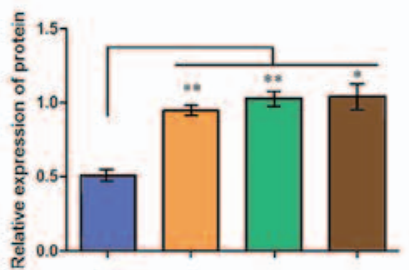

NFs alone

NFs with UM1
HK2

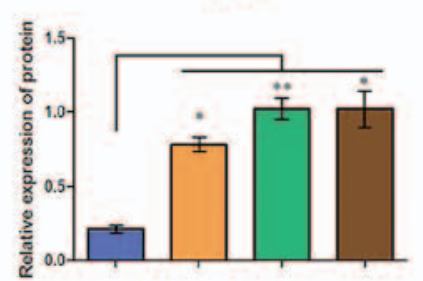

MCT4

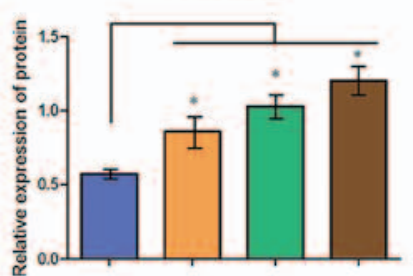

$\square$ NFs with CAL27

NFs with SCC25

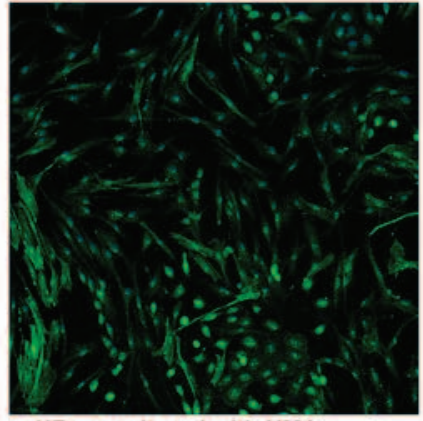

NFs cocultured with UM1
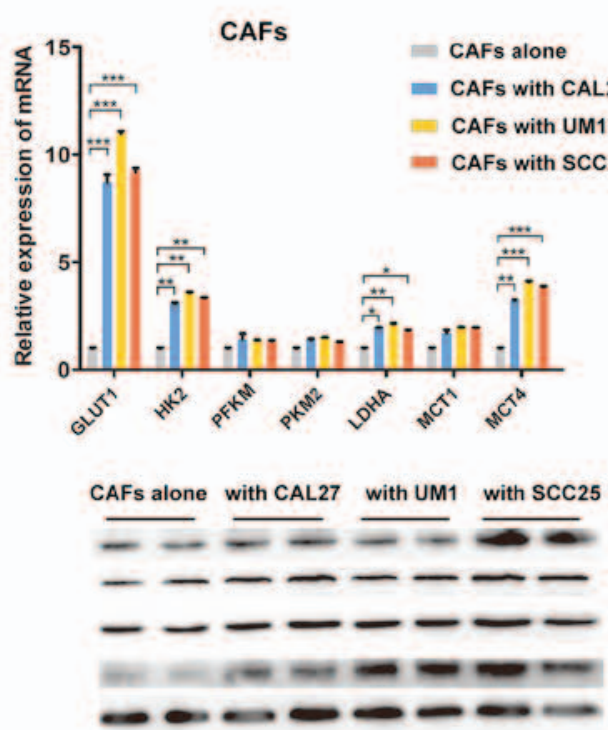

GLUT1
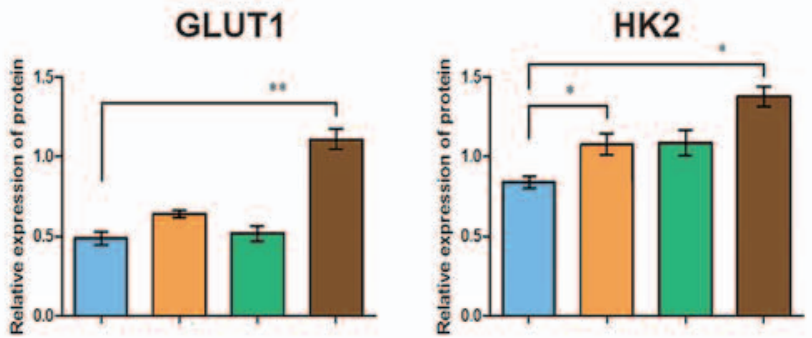

LDHA

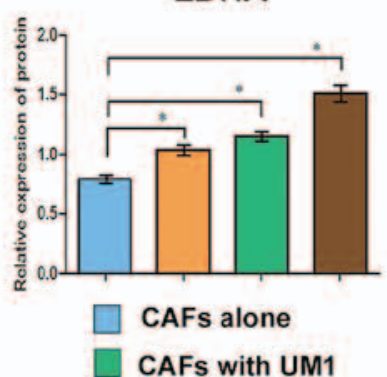

Figure 2. Oral cancer cells enhanced glycolysis of fibroblasts. (A) $\alpha$-smooth muscle actin (green) staining in NFs cultured alone and NFs co-cultured with UM1 cells. Magnification, x50. Fibroblasts (NFs and CAFs) were co-cultured with oral squamous cell carcinoma cell lines (CAL27, UM1 and SCC25) respectively, for $48 \mathrm{~h}$ before harvest. (B) Reverse transcription-quantitative polymerase chain reaction analysis for the expression of a series of glycolytic genes in fibroblasts. Columns present the mean \pm SD of triplicate determinations. (C) Western blot analysis of GLUT1, HK2, LDHA and MCT4 in NFs and CAFs. Densitometry was used to determine target gene/GAPDH ratios. Data are presented as the mean \pm SD of three independent experiments. ${ }^{*}<0.05$ and ${ }^{* *} \mathrm{P}<0.01$ vs. cells cultured alone. SD, standard deviation; NF, normal fibroblasts; CAFs, cancer-associated fibroblasts; GLUT1, glucose transporter 1; HK2, hexokinase 2; PFK, phosphofructokinase; PKM2, pyruvate kinase M2; LDHA, lactate dehydrogenase; MCT, mono-carboxylate transporter.

MCT1 and increased expression of MCT4, compared with untreated controls, respectively (Fig. 5B). However, when
UM1 cells were transfected with si-IL-1 $\beta$, GLUT1, LDHA and MCT4 expression significantly decreased, compared with the 

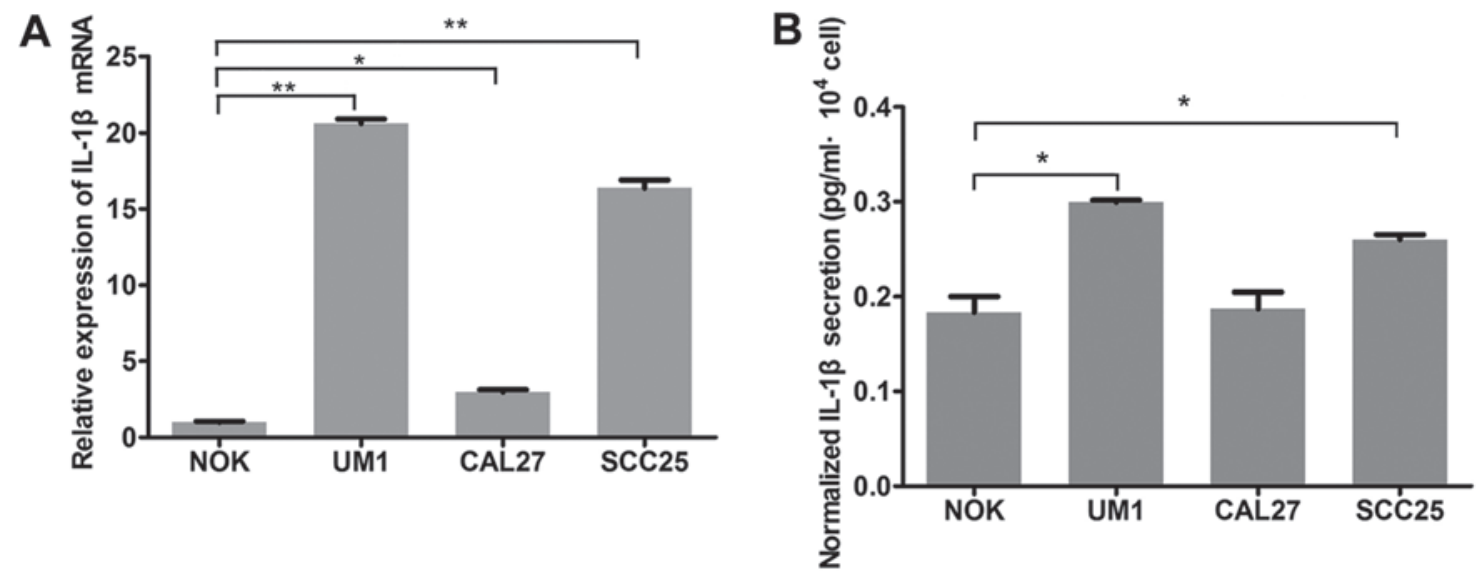

Figure 3. IL-1 $\beta$ is overexpressed in OSCC cells. (A) Reverse transcription-quantitative polymerase chain reaction and (B) ELISA analysis for IL-1 $\beta$ expression and secretion of OSCC cell lines (UM1, CAL27 and SCC25) and keratinocyte (NOK) cells. The data are presented as the mean \pm standard deviation of three independent experiments. ${ }^{*} \mathrm{P}<0.05$ and $^{* *} \mathrm{P}<0.01$ vs. NOK cells. OSCC, oral squamous cell carcinoma; IL-1 $\beta$, interleukin- $1 \beta$.

A

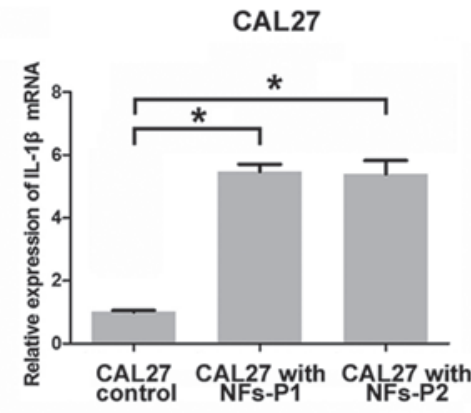

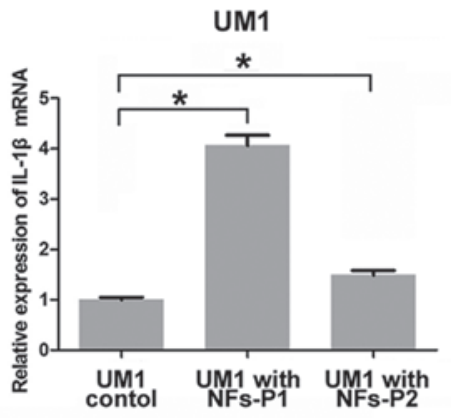

UM1

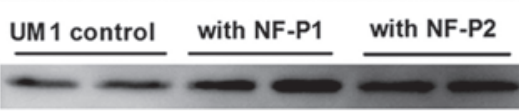

$\mathrm{IL}-1 \beta$

Tubulin

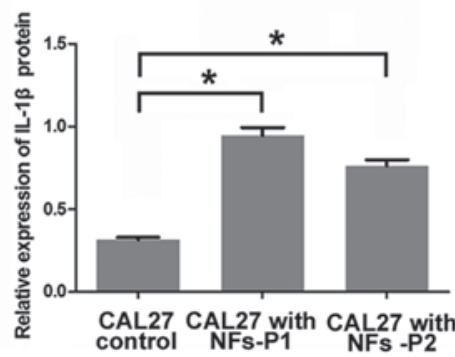

CAL27

CAL27 control with NF-P1 with NF-P2

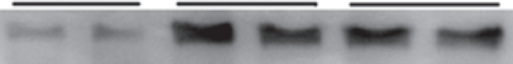

control NFs-P1 NFs -P2

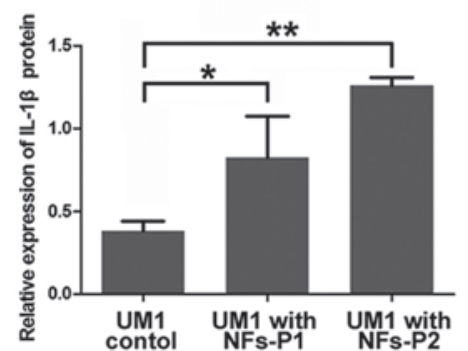

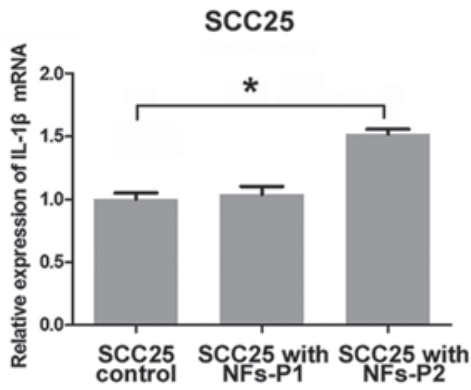

Figure 4. Fibroblasts stimulate IL-1ß expression in OSCC cells. OSCC cell lines (CAL27, UM1 and SCC25) were continuously co-cultured with NFs for two passages (P1 and P2). (A) Reverse transcription-quantitative polymerase chain reaction and (B) western blot analysis of IL-1 $\beta$ expression in OSCC cells co-cultured with NFs. Densitometry was used to determine IL-1 $\beta /$ tubulin ratios. Columns represent the mean \pm standard deviation of triplicate determinations. ${ }^{*} \mathrm{P}<0.05$ and ${ }^{* *} \mathrm{P}<0.01$. OSCC, oral squamous cell carcinoma; IL-1 $\beta$, interleukin-1 $\beta$.

negative control siRNA group, (Fig. 5C). Collectively, these observations indicated that IL-1 $\beta$ stimulates glycolysis of activated oral fibroblasts.

Fibroblasts promote lactate uptake and proliferation of OSCC. The aforementioned findings demonstrated that oral cancer cells enhanced stromal glycolysis in the activated fibroblasts by secreting increased IL- $1 \beta$, which resulted in MCT4 (a lactate excretion transporter) upregulation in fibroblasts. To further investigate the lactate destination and OSCC response to this, the lactate uptake transporter MCT1 expression and cell proliferation of OSCC cells in the 
A
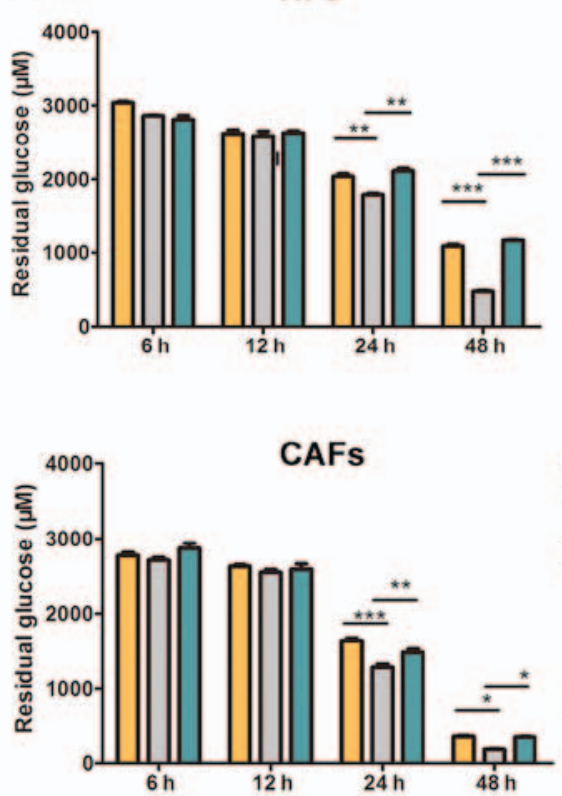

$\square$ control

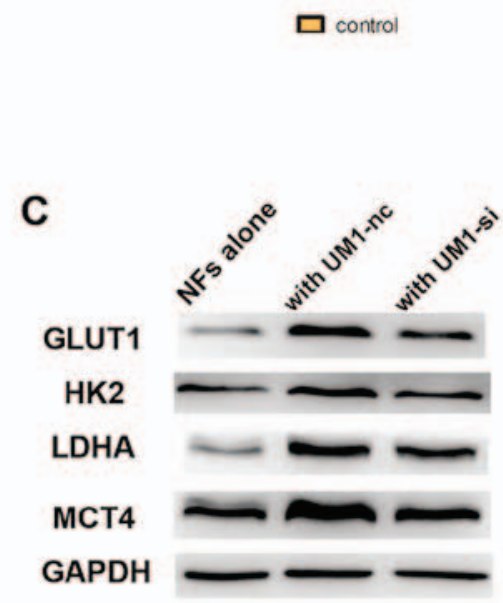

NFs
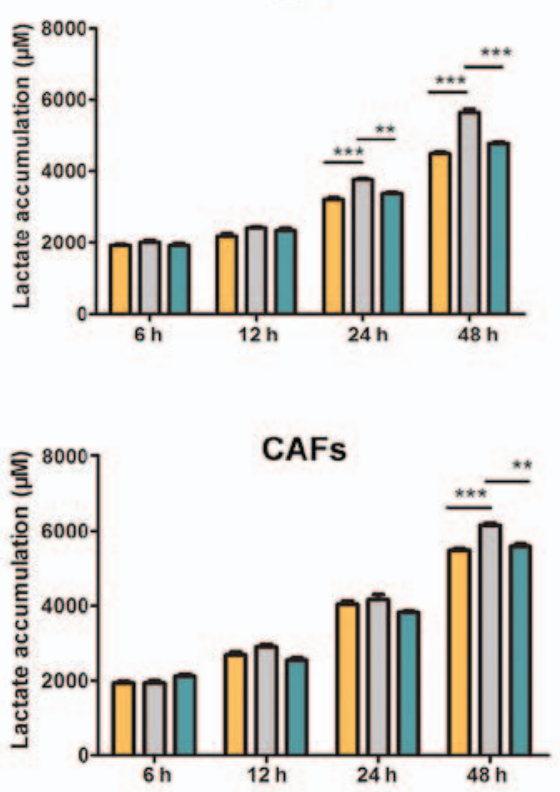

$\square \mathbb{I L}-1 \mathrm{~B} \quad \square \mathrm{IL}-1 \beta+\mathbb{I L} 1-\mathrm{Ra}$
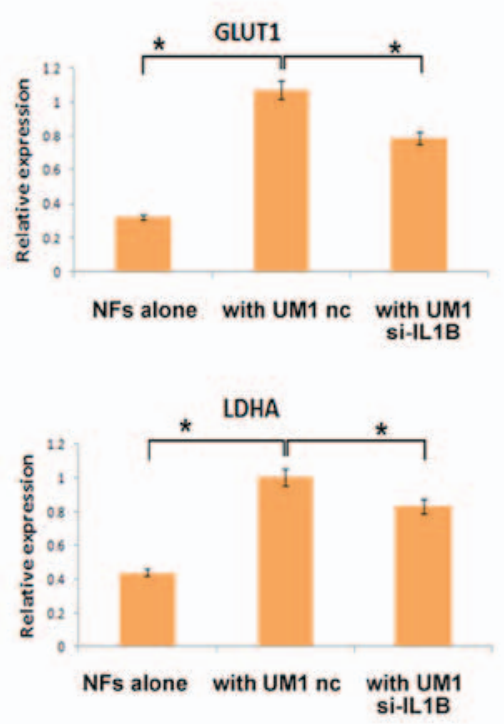

B
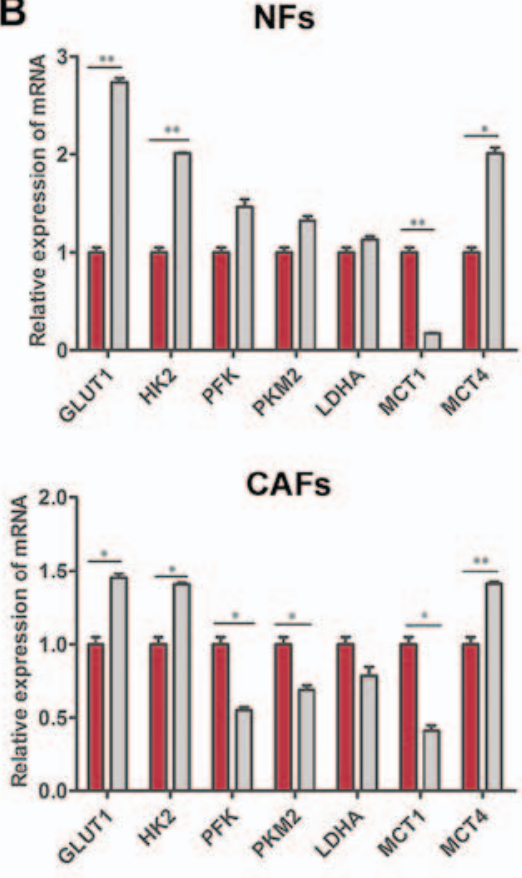

control
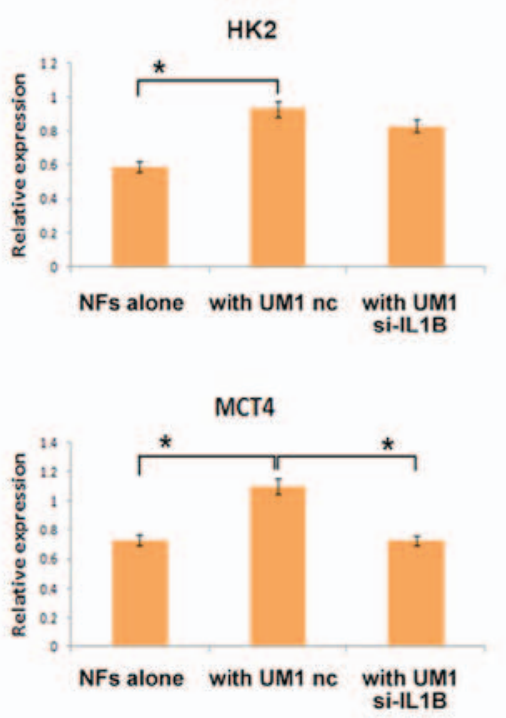

Figure 5. Tumor-derived IL-1 $\beta$ induces stromal glycolysis. (A) NFs and CAFs were treated with $20 \mathrm{ng} / \mathrm{ml} \mathrm{IL}-1 \beta$ alone or $20 \mathrm{ng} / \mathrm{ml} \mathrm{IL}-1 \beta+20 \mathrm{mg} / \mathrm{ml} \mathrm{IL}-1 \mathrm{Ra}$ for $48 \mathrm{~h}$. CM were harvested at $6,12,24$ and $48 \mathrm{~h}$ for residual glucose and lactate consumption analysis using glucose and lactate assay kits, respectively. (B) NFs and CAFs treated with $20 \mathrm{ng} / \mathrm{ml} \mathrm{IL-1 \beta}$ were collected for reverse transcription-quantitative polymerase chain reaction assays. Columns represent the mean \pm standard deviation of three independent experiments. ${ }^{*} \mathrm{P}<0.05,{ }^{* *} \mathrm{P}<0.01$ and ${ }^{* * *} \mathrm{P}<0.001$. (C) NFs and UM1 cells transfected with $10 \mathrm{nM}$ nc or $10 \mathrm{nM}$ si-IL1B were co-cultured for $48 \mathrm{~h}$. NFs were then harvested for western blot analysis of GLUT1, HK2, LDHA and MCT4. Densitometry was used to determine target gene/GAPDH ratios. *P<0.05 vs. UM1-nc group. IL-1 $\beta$, interleukin-1 $\beta$; NFs, normal fibroblasts; CAFs, cancer-associated fibroblasts; IL-1Ra, interleukin-1 receptor antagonist; GLUT1, glucose transporter 1; HK2, hexokinase 2; LDHA, lactate dehydrogenase; MCT, mono-carboxylate transporter; siRNA, small interfering RNA; nc, negative control siRNA; si-IL1B, IL-1 $\beta$ siRNA.

co-culture system was examined. In UM1 and SCC25 cells, MCT1 protein expression increased in a time-dependent manner, and in CAL27 cells there was significant upregulation of MCT1 in the first passage of cultivation (Fig. 6A-C). UM1 cells were pre-stained with CFSE dye (which is equally distributed to two daughter cells during mitosis), and then co-cultured with NFs to detect the effect of stromal-epithelial lactate shuttle on OSCC cell proliferation. As shown in Fig. 6D, the proliferation index of UM1 cells in the co-culture group was significantly higher than that in UM1 cells cultured alone after 48 and $72 \mathrm{~h}$ (Fig. 6D). The above data suggest that lactate shuttle from activated oral fibroblasts to oral cancer cells promotes cancer cell proliferation.

\section{Discussion}

Increasing evidence has highlighted the importance of reciprocal metabolic reprogramming and lactate shuttling in epithelial malignancies. However, the stromal-epithelial lactate shuttle and the underlying mechanisms during oral carcinogenesis still 
A
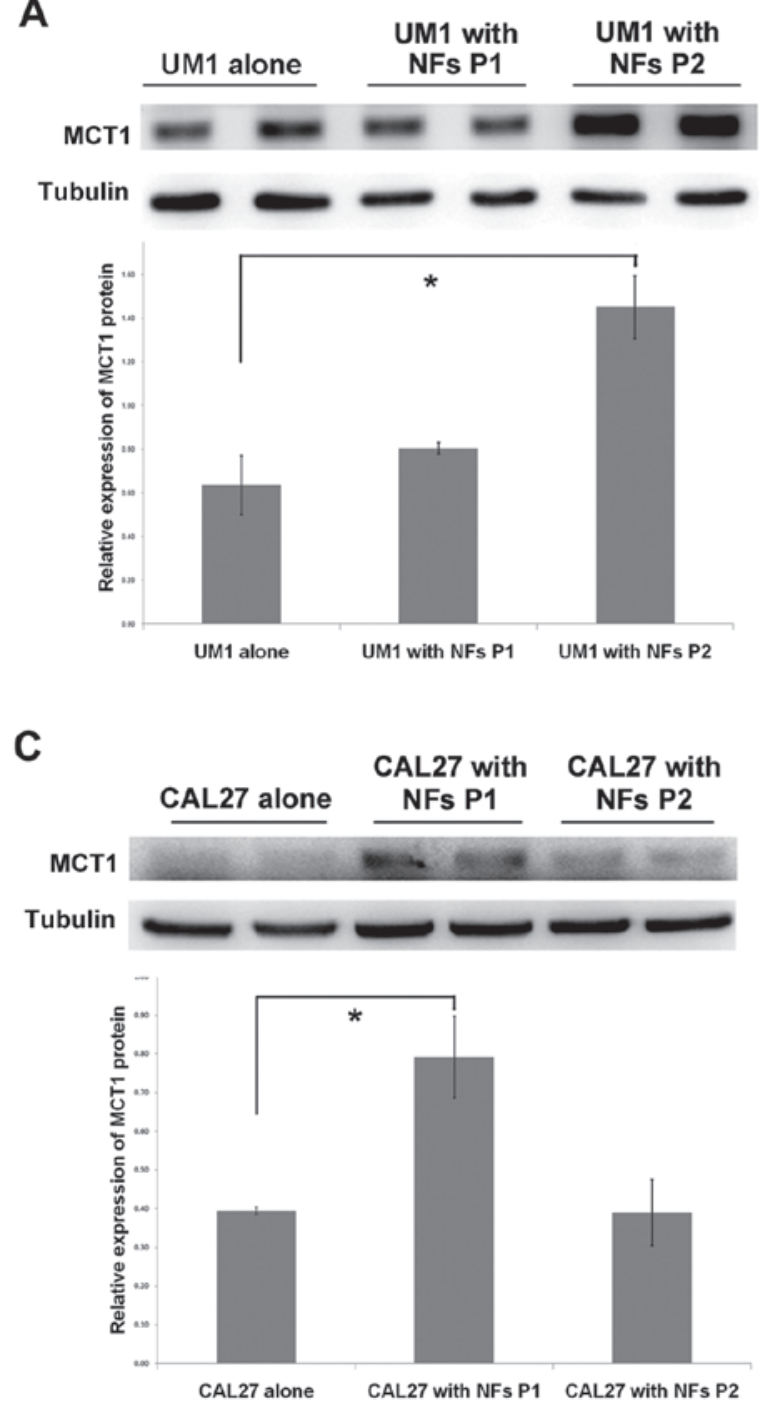

B

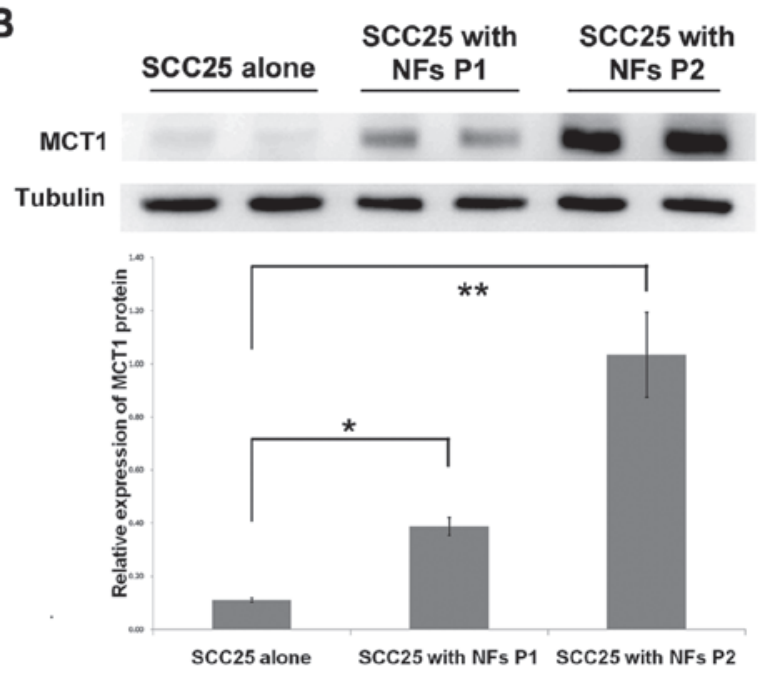

D

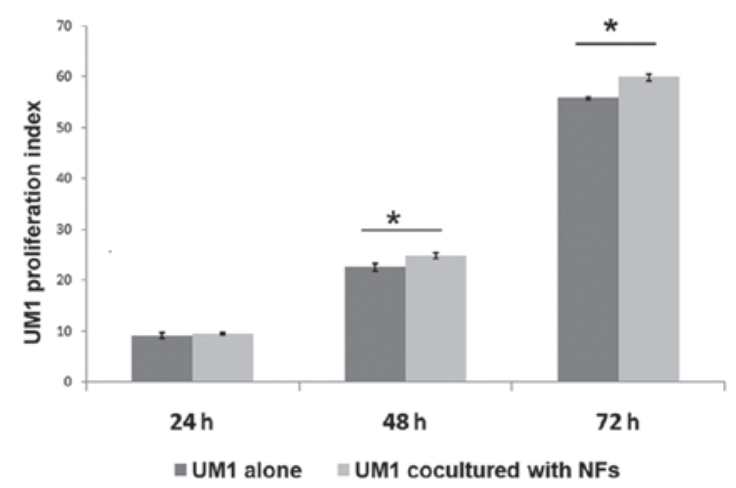

Figure 6. Fibroblasts promote MCT1 expression and proliferation of OSCC cells. OSCC cell lines (A) UM1, (B) SCC25 and (C) CAL27 and normal NFs were co-cultured for two passages. MCT1 expression of OSCC cell lines was detected by western blot assay. Densitometry was used to determine MCT1/tubulin ratios. "P<0.05. (D) Carboxy-fluorescein succinimidyl ester pre-stained UM1 and NFs were co-cultured for $72 \mathrm{~h}$, and these UM1 cells were collected and fixed every $24 \mathrm{~h}$ until flow cytometry analysis. The histogram presented the fluorescence signals at $488 \mathrm{~nm}$ exciting light and proliferation index (represent the mean \pm standard deviation of three independent experiments) was calculated according to the signal profile. ${ }^{*} \mathrm{P}<0.05$ and ${ }^{* *} \mathrm{P}<0.01$. OSCC, oral squamous cell carcinoma; NFs, normal fibroblasts; P, passage; MCT1, mono-carboxylate transporter 1.

remain elusive. CAFs, also known as activated fibroblasts, are the biggest population of cancer stromal cells and differ from NFs in many respects, particularly epigenetics (12). For example, CAFs usually present with a caveolin-1 (cav-1) loss (13) and express active markers such as $\alpha$-SMA, stromal cell derived factor-1 (14) and fibroblast activation protein (15). Gene expression analysis demonstrated that the activated fibroblasts, CAFs, secrete a large amount of proteins and enzymes that disrupt the extracellular matrix, recruit immunocytes, and promote angiogenesis and metastasis (16). The findings of the current study demonstrated that fibroblasts from different stages of OSCC progression, NFs, Dysplasia-fs and CAFs, displayed increased $\alpha$-SMA expression, which suggested that the fibroblasts were activated during oral carcinogenesis. Additionally, these fibroblasts also exhibited increased glucose uptake and lactate accumulation in their supernatant, which indicated that glycolysis was enhanced fibroblasts from the TME. The increase in glycolysis in fibroblasts had been demonstrated in various solid human tumors (17). Pavlides et al (17), Bonuccelli et al (18) and Pavlides et al (19) reported that glycolytic enzymes were unregulated in CAFs with cav-1 loss, and they proposed that hydrogen peroxide secreted by cancer cells induced oxidative stress, mitophagy and aerobic glycolysis in CAFs.

It has been previously reported that cancer cells utilize fibroblast-produced intermediate products, such as lactate, ketone and glutamine, as nutrient substances (20). In human prostate cancer, tracing experiments explicitly demonstrated the lactate flows from fibroblasts to cancer cells in a common co-culture system. This metabolic symbiosis phenomenon was an important supplement to the Warburg effect, termed the 'reverse Warburg effect', which indicates that there must be a reciprocal metabolic influence between CAFs and cancer cells. In the current study, co-culture with OSCC cells significantly enhanced glycolytic gene expression in fibroblasts.

Our recent study identified IL-1 $\beta$ as a key node gene during oral carcinogenesis, both in epithelium and sub-mucosal 
fibroblasts. Notably, the IL-1 $\beta$ expression in epithelium increased gradually as oral malignancy progressed (10). Inversely, saliva exosome analysis of patients with OSCC revealed that secretory IL-1 $\beta$ significantly decreased following surgical treatment (21). OSCC cells were further confirmed as the source of intercellular IL-1 $\beta$. In the current study, it was confirmed that IL-1 $\beta$ expression and secretion were upregulated in OSCC cell lines (UM1, SCC25 and CAL27). In the co-culture system, activated fibroblasts stimulated IL-1 $\beta$ expression in OSCC cells. Since the co-culture system imitated the epithelial-stromal interaction in vivo, it is deduced that activated fibroblasts participate in promoting IL- $1 \beta$ production in premalignant and malignant oral epithelium, and this substantial tumor-derived IL-1 $\beta$ may be a vital signal mediating epithelium-mesenchyme dialogue.

The results of the present study demonstrated that IL- $1 \beta$ expression in OSCC, activation of fibroblasts and aerobic glycolysis in fibroblasts were simultaneously enhanced during malignant progression of oral cancer cells. Does tumor-derived IL-1 $\beta$ enhance stromal glycolysis and induce lactate shuttle to the cancer cells? Further experiments demonstrated that exogenous IL-1 $\beta$-treated NFs consumed more glucose and release more lactate into the supernatant. At the same time, the expression of glycolysis and lactate emission-associated genes, such as GLUT1, HK2, LDHA and MCT4, was increased in the IL-1 $\beta$-treated NFs. Conversely, IL-Ra significantly abrogated the IL-1 $\beta$-induced glycolysis. Knockdown using si-IL-1 $\beta$ in UM1 cells effectively blocked the regulatory effect of OSCC on stromal glycolysis. For OSCC cells in the co-culture system, the lactate uptake transporter, MCT1 was correspondingly overexpressed. These differentially expressed genes pointed to the reverse Warburg effect, because GLUT1 is the predominant facilitative glucose transporter in human cells, and overexpression of GLUT1 usually predicts increased glucose uptake $(22,23)$. HK2 is a key rate-limiting enzyme in glycolysis, and LDHA catalyzes the conversion of pyruvate, a glycolysis mediator-production, into lactate $(24,25)$. MCT1/4 are vital lactate transporters involved in acid-base balance, and promoting glucose metabolism in tumor tissues (26). MCT4, usually expressed in glycolytic cells, is especially enriched in cells of high oxygen consumption, while MCT1 is rather ubiquitous (5).

MCT4 overexpression in CAFs and MCT1 overexpression in transformed epithelium are regarded as independent indicators of poor outcomes in human carcinoma (27). The intercellular coordination of MCT1/4 expression in fibroblasts and cancer cells strongly indicate a unidirectional lactate shuttle, from stromal cells to the cancer cells $(6,28,29)$. Thus, fibroblasts directly feed neighboring cancer cells via lactate. In this study, MCT4 in fibroblasts and MCT1 in OSCC cells were upregulated by the stromal-epithelial co-culture, suggesting that lactate may be transported to the oxidative cancer cells. Additionally, the proliferation of OSCC cells was accelerated following co-cultivation with the fibroblasts. All these findings support the regulatory function of IL-1 $\beta$ in the reverse Warburg effect and lactate reuse by cancer cells.

However, the underlying mechanism of IL-1 $\beta$-modulated metabolic reprogramming remains ambiguous. Preliminarily results demonstrated that hypoxia inducible factor-1 $\alpha(\mathrm{HIF}-1 \alpha)$ may be partially responsible (data not shown), as IL-1 $\beta$ directly promoted HIF-1 $\alpha$ expression in fibroblasts, which is a regulatory transcription factor of various metabolic genes (30). Other potential mechanism have also been reported, including that IL-1 $\beta$ induces accumulation of reactive oxygen species $(12,31)$, and that IL-1 $\beta$ directly activates caspases in mitochondria (32), resulting in TCA cycle inhibition and promotes fibroblasts to utilize glucose through an inefficient method, anaerobic glycolysis.

In conclusion, the results of the present study identified a regulatory loop between fibroblasts and oral cancer cells by which cancer cells activate fibroblasts and fibroblasts promote IL-1 $\beta$ expression in OSCC. In turn, this tumor-derived IL-1 $\beta$ induces lactate emission from fibroblasts to feed cancer cells as 'fuel'. The findings provide novel insight into the role of IL-1 $\beta$ and lactate shuttle in oral cancer, and provide new therapeutic targets for future OSCC treatment.

\section{Acknowledgements}

This study was supported by grants of the National Natural Science Foundation of China (nos. 81272948, 81200787 and 81371148).

\section{References}

1. Martinez-Outschoorn UE, Lisanti MP and Sotgia F: Catabolic cancer-associated fibroblasts transfer energy and biomass to anabolic cancer cells, fueling tumor growth. Semin Cancer Biol 25: 47-60, 2014

2. Paolicchi E, Gemignani F, Krstic-Demonacos M, Dedhar S, Mutti L and Landi S: Targeting hypoxic response for cancer therapy. Oncotarget 7: 13464-13478, 2016.

3. Witkiewicz AK, Whitaker-Menezes D, Dasgupta A, Philp NJ, Lin Z, Gandara R, Sneddon S, Martinez-Outschoorn UE, Sotgia F and Lisanti MP: Using the 'reverse Warburg effect' to identify high-risk breast cancer patients: Stromal MCT4 predicts poor clinical outcome in triple-negative breast cancers. Cell Cycle 11: 1108-1117, 2012.

4. Bröer S, Rahman B, Pellegri G, Pellerin L, Martin JL, Verleysdonk S, Hamprecht B and Magistretti PJ: Comparison of lactate transport in astroglial cells and monocarboxylate transporter 1 (MCT 1) expressing Xenopus laevis oocytes. Expression of two different monocarboxylate transporters in astroglial cells and neurons. J Biol Chem 272: 30096-30102, 1997.

5. Pérez-Escuredo J, Van Hée VF, Sboarina M, Falces J, Payen VL, Pellerin L and Sonveaux P: Monocarboxylate transporters in the brain and in cancer. Biochim Biophys Acta 1863: 2481-2497, 2016.

6. Whitaker-Menezes D, Martinez-Outschoorn UE, Lin Z, Ertel A, Flomenberg N, Witkiewicz AK, Birbe RC, Howell A, Pavlides S, Gandara R, et al: Evidence for a stromal-epithelial 'lactate shuttle' in human tumors: MCT4 is a marker of oxidative stress in cancer-associated fibroblasts. Cell Cycle 10: 1772-1783, 2011.

7. Huang G, Qian G and Cheng D: The effect of monocarboxylate transporter gene on the regulation of $\mathrm{pHi}$ and growth character in cancer cells. Zhonghua Jie He He Hu Xi Za Zhi 24: 666-670, 2001 (In Chinese).

8. Baba M, Inoue M, Itoh K and Nishizawa Y: Blocking CD147 induces cell death in cancer cells through impairment of glycolytic energy metabolism. Biochem Biophys Res Commun 374: 111-116, 2008.

9. O'Callaghan K, Palagano E, Butini S, Campiani G, Williams DC, Zisterer DM and O'Sullivan J: Induction of apoptosis in oral squamous carcinoma cells by pyrrolo-1,5-benzoxazepines. Mol Med Rep 12: 3748-3754, 2015.

10. Wu T, Hong Y, Jia L, Wu J, Xia J, Wang J, Hu Q and Cheng B: Modulation of IL-1 $\beta$ reprogrammes the tumor microenvironment to interrupt oral carcinogenesis. Sci Rep 6: 20208, 2016. 
11. Livak KJ and Schmittgen TD: Analysis of relative gene expression data using real-time quantitative PCR and the 2(-Delta Delta C(T)) method. Methods 25: 402-408, 2001

12. Wang SN, Xie GP, Qin CH, Chen YR, Zhang KR, Li X, Wu Q, Dong WQ, Yang J and Yu B: Aucubin prevents interleukin-1 beta induced inflammation and cartilage matrix degradation via inhibition of NF- $\kappa \mathrm{B}$ signaling pathway in rat articular chondrocytes. Int Immunopharmacol 24: 408-415, 2015

13. Shen XJ, Zhang H, Tang GS, Wang XD, Zheng R, Wang Y, Zhu Y, Xue XC and Bi JW: Caveolin-1 is a modulator of fibroblast activation and a potential biomarker for gastric cancer. Int J Biol Sci 11: 370-379, 2015

14. Al-Rakan MA, Colak D, Hendrayani SF, Al-Bakheet A, Al-Mohanna FH, Kaya N, Al-Malik O and Aboussekhra A: Breast stromal fibroblasts from histologically normal surgical margins are pro-carcinogenic. J Pathol 231: 457-465, 2013.

15. Mundim FG, Pasini FS, Nonogaki S, Rocha RM, Soares FA, Brentani MM and Logullo AF: Breast carcinoma-associated fibroblasts share similar biomarker profiles in matched lymph node metastasis. Appl Immunohistochem Mol Morphol 24: 712-720, 2016.

16. Tang D, Gao J, Wang S, Ye N, Chong Y, Huang Y, Wang J, Li B, Yin W and Wang D: Cancer-associated fibroblasts promote angiogenesis in gastric cancer through galectin-1 expression. Tumour Biol 37: 1889-1899, 2016.

17. Pavlides S, Whitaker-Menezes D, Castello-Cros R, Flomenberg N, Witkiewicz AK, Frank PG, Casimiro MC, Wang C, Fortina P, Addya S, et al: The reverse Warburg effect: Aerobic glycolysis in cancer associated fibroblasts and the tumor stroma. Cell Cycle 8: 3984-4001, 2009.

18. Bonuccelli G, Whitaker-Menezes D, Castello-Cros R, Pavlides S, Pestell RG, Fatatis A, Witkiewicz AK, Vander Heiden MG, Migneco G, Chiavarina B, et al: The reverse Warburg effect: Glycolysis inhibitors prevent the tumor promoting effects of caveolin-1 deficient cancer associated fibroblasts. Cell Cycle 9: 1960-1971, 2010

19. Pavlides S, Vera I, Gandara R, Sneddon S, Pestell RG, Mercier I, Martinez-Outschoorn UE, Whitaker-Menezes D, Howell A, Sotgia F, et al: Warburg meets autophagy: Cancer-associated fibroblasts accelerate tumor growth and metastasis via oxidative stress, mitophagy, and aerobic glycolysis. Antioxid Redox Signal 16: 1264-1284, 2012.

20. Capparelli C, Guido C, Whitaker-Menezes D, Bonuccelli G, Balliet R, Pestell TG, Goldberg AF, Pestell RG, Howell A, Sneddon S, et al: Autophagy and senescence in cancer-associated fibroblasts metabolically supports tumor growth and metastasis via glycolysis and ketone production. Cell Cycle 11: 2285-2302, 2012.

21. Kamatani T, Shiogama S, Yoshihama Y, Kondo S, Shirota T and Shintani S: Interleukin-1 beta in unstimulated whole saliva is a potential biomarker for oral squamous cell carcinoma. Cytokine 64: 497-502, 2013.

22. Venturelli L, Nappini S, Bulfoni M, Gianfranceschi G, Dal Zilio S, Coceano G, Del Ben F, Turetta M, Scoles G, Vaccari $\mathrm{L}$, et al: Glucose is a key driver for GLUT1-mediated nanoparticles internalization in breast cancer cells. Sci Rep 6: 21629, 2016.
23. Brito AF, Abrantes AM, Ribeiro M, Oliveira R, Casalta-Lopes J, Gonçalves AC, Sarmento-Ribeiro AB, Tralhão JG and Botelho MF: Fluorine-18 fluorodeoxyglucose uptake in hepatocellular carcinoma: Correlation with glucose transporters and p53 expression. J Clin Exp Hepatol 5: 183-189, 2015.

24. Ma Y, Yu C, Mohamed EM, Shao H, Wang L, Sundaresan G, Zweit J, Idowu M and Fang X: A causal link from ALK to hexokinase II overexpression and hyperactive glycolysis in EML4-ALK-positive lung cancer. Oncogene 35: 6132-6142, 2016.

25. Masoud GN and Li W: HIF-1 $\alpha$ pathway: Role, regulation and intervention for cancer therapy. Acta Pharm Sin B 5: 378-389, 2015.

26. Choi SY, Xue H, Wu R, Fazli L, Lin D, Collins CC, Gleave ME, Gout PW and Wang Y: The MCT4 gene: A novel, potential target for therapy of advanced prostate cancer. Clin Cancer Res 22: 2721-2733, 2016.

27. Lisanti MP, Sotgia F, Pestell RG, Howell A and Martinez-Outschoorn UE: Stromal glycolysis and MCT4 are hallmarks of DCIS progression to invasive breast cancer. Cell Cycle 12: 2935-2936, 2013

28. Andersen S, Solstad Ø, Moi L, Donnem T, Eilertsen M, Nordby Y, Ness N, Richardsen E, Busund LT and Bremnes RM: Organized metabolic crime in prostate cancer: The coexpression of MCT1 in tumor and MCT4 in stroma is an independent prognosticator for biochemical failure. Urol Oncol 33: 338.e339-317, 2015.

29. Pértega-Gomes N, Vizcaíno JR, Attig J, Jurmeister S, Lopes C and Baltazar F: A lactate shuttle system between tumour and stromal cells is associated with poor prognosis in prostate cancer. BMC Cancer 14: 352, 2014.

30. Martinez-Outschoorn UE, Trimmer C, Lin Z, Whitaker-Menezes D, Chiavarina B, Zhou J, Wang C, Pavlides S, Martinez-Cantarin MP, Capozza F, et al: Autophagy in cancer associated fibroblasts promotes tumor cell survival: Role of hypoxia, HIF1 induction and NFKB activation in the tumor stromal microenvironment. Cell Cycle 9: 3515-3533, 2010.

31. Vallejo S, Palacios E, Romacho T, Villalobos L, Peiró C and Sánchez-Ferrer CF: The interleukin-1 receptor antagonist anakinra improves endothelial dysfunction in streptozotocin-induced diabetic rats. Cardiovasc Diabetol 13: 158, 2014.

32. Vecile E, Dobrina A, Salloum FN, Van Tassell BW, Falcione A, Gustini E, Secchiero S, Crovella S, Sinagra G, Finato N, et al: Intracellular function of interleukin-1 receptor antagonist in ischemic cardiomyocytes. PLoS One 8: e53265, 2013.

This work is licensed under a Creative Commons Attribution-NonCommercial-NoDerivatives 4.0 International (CC BY-NC-ND 4.0) License. 